\title{
IMPLICATIONS OF FAULT CURRENT LIMITATION FOR ELECTRICAL DISTRIBUTION NETWORKS
}

\author{
S.M. Blair*, A.J. Roscoe*, C.D. Booth*, G.M. Burt *, A. Teo ${ }^{\dagger}$ and C.G. Bright ${ }^{\dagger}$ \\ * Institute for Energy and Environment, University of Strathclyde, Glasgow, UK, steven.blair@eee.strath.ac.uk \\ † Rolls-Royce, Derby, UK, anita.teo@rolls-royce.com
}

Keywords: Distributed generation, fault current limitation, fault level, protection, SFCL.

\begin{abstract}
This paper explores the potential future need for fault current limitation in the UK's power system, and some of the technical implications of this change. It is estimated that approximately 300-400 distribution substations will require fault current limitation, based on the statistical analysis of the projected fault level "headroom" (or violation). The analysis uses a UK electrical system scenario that satisfies the Government's target for an $80 \%$ cut in $\mathrm{CO}_{2}$ emissions by 2050. A case study involving the connection of distributed generation (DG) via a superconducting fault current limiter (SFCL) is used to illustrate the potential protection and control issues. In particular, DG fault ride-through, autoreclosure schemes, and transformer inrush current can be problematic for SFCLs that require a recovery period. The potential solutions to these issues are discussed, such as the use of islanding or automation to reduce the fault level.
\end{abstract}

\section{Introduction}

Utility electrical distribution systems require new solutions to address the problems presented by increased fault current levels due to the connection of distributed generation (DG) and energy storage. There are several methods of reducing fault currents [2]; this paper focuses on the resistive superconducting fault current limiter (SFCL). The future need for fault current limitation in distribution networks is statistically analysed, based on the projected fault level "headroom" (or violation). An increased presence of DG and fault current limitation in the electrical system requires close examination of the system-wide integration issues, particularly for protection and control schemes, such as fault ride-through and auto-reclosure. An important theme of this paper is the problem of the recovery time of resistive SFCLs and how it impacts protection, as well as potential solutions.

\section{Analysis of need for fault current limitation}

\subsection{Summary of analysis method}

The present-day fault level headroom is derived from publicly available five-year plan documents for three UK distribution network operators (DNOs). In this analysis, DNOs A and B provide an urban/rural mix, and DNO C is highly "rurallybiased". The headroom is calculated from switchgear equipment ratings minus RMS break fault levels. The mean and standard deviation of the headroom at each voltage level, for each DNO, are calculated. Data from different DNOs are merged and the number of substations (nodes) is scaled to approximate a UK-wide scenario.

A future scenario for UK generation to satisfy the Government's target for an $80 \%$ cut in $\mathrm{CO}_{2}$ emissions by 2050 [12] is established, including the required DG and energy storage, and their distribution in the electrical system. However, this scenario may be idealistic and is simply indicative of the possible impact of generation on fault levels. The increase in mean fault level (and corresponding decrease in mean headroom) due to the future scenario is calculated. A DG connection at a single node may also raise the fault level at neighbouring nodes. To model this effect, it has been estimated that any DG installation increases the fault current, on average, at 1.5 nodes. Hence, the number of "independent nodes" is defined as the actual number of nodes divided by 1.5. The percentage of power system substations which are likely to have negative fault level headroom, hence requiring some form of fault current limitation, is statistical analysed.

\subsection{Results}

Figure 1 illustrates the fault level relative to circuit breaker (CB) rating for DNO A. At both $11 \mathrm{kV}$ and $33 \mathrm{kV}$, DNO A was found to have the worst mean fault level headroom, 6.7 $\mathrm{kA}$ and $6.9 \mathrm{kA}$ respectively. Table 1 summarises the overall headroom for all DNOs. The weighted averages of existing "over-stressed" nodes are $2.5 \%$ for $11 \mathrm{kV}$ and $1.4 \%$ for 33 $\mathrm{kV}$.

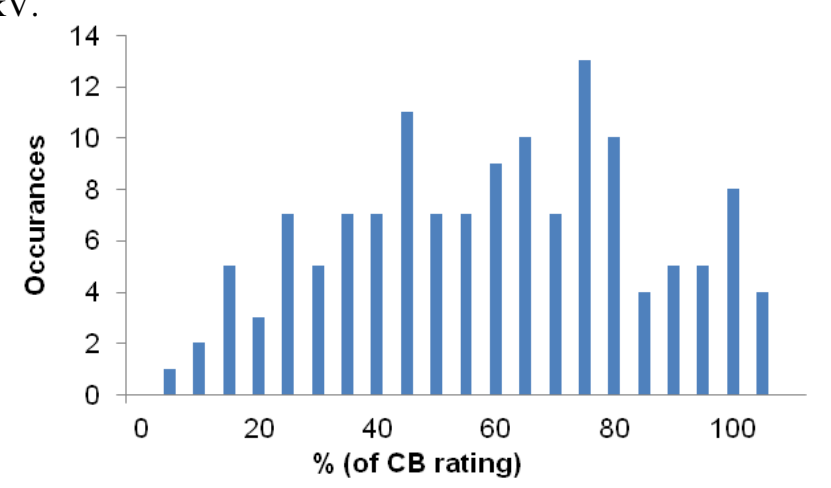

Figure 1: RMS break fault level as a percentage of $\mathrm{CB}$ rating, for DNO A at $33 \mathrm{kV}$ 


\begin{tabular}{|c|c|c|}
\cline { 2 - 3 } \multicolumn{1}{c|}{} & $\mathbf{1 1} \mathbf{~ k V}$ & $\mathbf{3 3 ~ k V}$ \\
\hline Total valid nodes & 1147 & 698 \\
\hline Fault level mean (\% of CB rating) & $48.6 \%$ & $47.1 \%$ \\
\hline 3-phase fault level mean & $7.1 \mathrm{kA}$ & $8.0 \mathrm{kA}$ \\
\hline 3-phase fault level std. dev. & $3.0 \mathrm{kA}$ & $4.0 \mathrm{kA}$ \\
\hline Mean CB rating & $15.0 \mathrm{kA}$ & $17.9 \mathrm{kA}$ \\
\hline Mean headroom & $7.9 \mathrm{kA}$ & $9.9 \mathrm{kA}$ \\
\hline
\end{tabular}

Table 1: Summary of fault level headroom (averages for all DNOs, weighted by relative peak demand)

The UK 2050 scenario used in this paper requires approximately $59.2 \mathrm{GWa}$ (gigawatt-years) of electrical energy. This is significantly higher than the 2007 demand of 39 GWa (342 TWh), due to the impact of electric vehicles (EVs) and the increased use of electricity for space heating (using heat pumps where appropriate, displacing natural gas use). Assuming an average load factor of 0.83 (if heating, EV-charging, and electrolysis loads can be managed, via demand response and real-time pricing, to have load factors of 1) and a transmission and distribution efficiency of $91 \%$, there is a peak electrical demand of $70.9 \mathrm{GW}$ (at the end user) or $77.9 \mathrm{GW}$ at generation. In this scenario, $25.5 \mathrm{GWa}$ would come from "traditional" generation sources, and the remaining $33.7 \mathrm{GWa}$ from renewable or sustainable sources (or energy storage). The derivation of these values is beyond the scope of this paper. An estimated split of renewable generation sources, and their assumed capacity factors, is shown in Table 2.

\begin{tabular}{|c|c|c|c|c|}
\cline { 2 - 5 } \multicolumn{1}{c|}{} & $\begin{array}{c}\text { \% required } \\
\text { from each } \\
\text { source }\end{array}$ & $\begin{array}{c}\text { Capacity } \\
\text { factor }\end{array}$ & $\begin{array}{c}\text { Total } \\
\text { energy } \\
\text { required }\end{array}$ & $\begin{array}{c}\text { Peak } \\
\text { capacity }\end{array}$ \\
\hline Wind & $60.0 \%$ & 0.35 & $22.7 \mathrm{GWa}$ & $64.9 \mathrm{GW}$ \\
\hline Tidal & $20.0 \%$ & 0.42 & $7.8 \mathrm{GWa}$ & $18.6 \mathrm{GW}$ \\
\hline Wave & $10.0 \%$ & 0.35 & $4.1 \mathrm{GWa}$ & $11.7 \mathrm{GW}$ \\
\hline Solar & $5.0 \%$ & 0.12 & $2.7 \mathrm{GWa}$ & $22.2 \mathrm{GW}$ \\
\hline $\begin{array}{c}\text { Despatchable } \\
\text { renewables } \\
\text { (Biomass etc.) }\end{array}$ & $5.0 \%$ & 0.60 & $1.9 \mathrm{GWa}$ & $3.1 \mathrm{GW}$ \\
\hline Storage & $N / A$ & 0.25 & $5.1 \mathrm{GWa}$ & $20.5 \mathrm{GW}$ \\
\hline
\end{tabular}

Table 2: Peak capacities of renewable generation and storage to meet 2050 targets

In the worst case scenario where only despatchable renewable sources are available (3.1 GW), and given a despatchable (non-renewable) peak capacity of $54.3 \mathrm{GW}$, the minimum peak capacity of energy storage must be $20.5 \mathrm{GW}$. Considering an average capacity factor of 0.25 for storage devices and an assumed average efficiency of 59\% for the energy storage process, $5.1 \mathrm{GWa}$ of energy must pass through storage, with losses of $2.1 \mathrm{GWa}$. Hence, a total of $39.1 \mathrm{GWa}$ $(33.7 \div 0.91+2.1)$ must be provided from sustainable sources.

\begin{tabular}{|c|c|c|c|}
\cline { 2 - 4 } \multicolumn{1}{c|}{} & \multicolumn{3}{c|}{ Symmetrical per-unit short-circuit current infeed } \\
\cline { 2 - 4 } \multicolumn{1}{c|}{ Synchronous } & $\mathbf{1 1} \mathbf{~ k V}$ & $\mathbf{3 3} \mathbf{~ k V}$ & $\mathbf{1 3 2} \mathbf{~ k V}$ \\
\hline \multirow{2}{*}{ DFIG } & $\begin{array}{c}3-8 \text { (direct } \\
\text { connected) }\end{array}$ & $\begin{array}{c}3-8 \text { (direct } \\
\text { connected) }\end{array}$ & $\begin{array}{c}2.5-4.5 \text { (always } \\
\text { via a transformer) }\end{array}$ \\
\hline \multirow{2}{*}{ Inverter } & $\begin{array}{c}1.0-2.0 \text { (direct } \\
\text { connected) }\end{array}$ & $\begin{array}{c}1.0-2.0 \text { (direct } \\
\text { connected) }\end{array}$ & $\begin{array}{c}1.0-1.5 \text { (always } \\
\text { via a transformer) }\end{array}$ \\
\hline & $\begin{array}{c}1.0-2.0 \text { (direct } \\
\text { connected) }\end{array}$ & $\begin{array}{c}1.0-2.0 \text { (possibly } \\
\text { direct connected) }\end{array}$ & $\begin{array}{c}1.0-1.5 \text { (always } \\
\text { via a transformer) }\end{array}$ \\
\hline
\end{tabular}

Table 3: Ranges of symmetrical fault level in-feeds for different interface types
The mix of generation-to-grid interfaces is important for estimating the likely fault current contributions from DG. Wind sources commonly use a double fed induction generator (DFIG) interface. Tidal, wave, solar, and storage sources are typically inverter-interfaced, with the exception of hydro generation and compressed-air which are synchronous. Despatchable renewables are also assumed to be synchronous generators. The typical fault level in-feed ranges, adapted from [6], are shown in Table 3; the mean and standard deviation values of each range are used in the analysis.

\begin{tabular}{|c|c|c|c|}
\cline { 2 - 4 } \multicolumn{1}{c|}{} & $\mathbf{1 1} \mathbf{~ k V}$ & $\mathbf{3 3} \mathbf{~ k V}$ & $\mathbf{1 3 2} \mathbf{~ k V}$ \\
\hline Wind, Tidal, Wave, and Biomass, etc. & $30 \%$ & $50 \%$ & $20 \%$ \\
\hline Solar & $80 \%$ & $20 \%$ & $0 \%$ \\
\hline Storage & $30 \%$ & $30 \%$ & $40 \%$ \\
\hline
\end{tabular}

Table 4: Likely split of new generation/storage capacities at each connection voltage

Given the estimated split of generation connection voltages in Table 4, the mean fault level increase per node at each voltage level can be determined. The mean headroom minus the mean contribution from each renewable generation interface type, at each "independent node", is calculated; the normally distributed variables are combined. The probability of nodes being overstressed (possessing negative headroom) can be calculated using one minus the cumulative normal distribution function (shown in Equation (1), where $x$ is the value of interest divided by the standard deviation).

$$
P(x)=\frac{1}{\sqrt{2 \pi}} \int_{-\infty}^{x} e^{\frac{-x^{2}}{2}} d x
$$

Multiplying the resulting probabilities by the number of nodes in the UK, at each voltage level, estimates the number of substations which may require fault current limitation, as summarised in Table 5. The analysis was repeated to consider DNOs A and B only, to exclude DNO C's rural bias.

\begin{tabular}{|l|c|c|c|c|}
\cline { 2 - 5 } \multicolumn{1}{c|}{} & \multicolumn{2}{c|}{ All three DNOs } & \multicolumn{2}{c|}{ DNOs A and B } \\
\cline { 2 - 5 } \multicolumn{1}{c|}{} & $\mathbf{1 1} \mathbf{~ k V}$ & $\mathbf{3 3 ~ k V}$ & $\mathbf{1 1 ~ k V}$ & $\mathbf{3 3 ~ k V}$ \\
\hline $\begin{array}{l}\text { Approx. percentage of } \\
\text { nodes with negative } \\
\text { headroom }\end{array}$ & $5.2 \%$ & $1.0 \%$ & $5.9 \%$ & $1.9 \%$ \\
\hline $\begin{array}{l}\text { Number of potentially } \\
\text { affected nodes in the } \\
\text { UK }\end{array}$ & 282 & 42 & 320 & 75 \\
\hline
\end{tabular}

Table 5: Potential UK-wide requirement for fault current limitation, at $11 \mathrm{kV}$ and $33 \mathrm{kV}$

\subsection{Assumptions and discussion}

The results illustrate that a significant number of UK substations, particularly at $11 \mathrm{kV}$, may require fault current limitation. Other countries faced with similar future DG connection may have similar issues with fault levels, indicating a worldwide market for SFCLs.

The analysis in this paper does not include specialist fault current limiter applications such as DC networks or marine vessel power systems. Local "clustering" of DG/power storage systems is not considered, even though the number of required installations required to meet 2050 targets is high; an 
even spread is assumed. Clustering would increase the fault level at individual nodes, but the number of nodes affected would reduce. Thus, an assumed homogeneous spread of DG/storage probably leads to a reasonably accurate estimate. This analysis does not account for new substations which may be needed to support the significant electrical demand increase, or the potential to purchase cheaper switchgear with a lower fault current rating (e.g., $16 \mathrm{kA}$ instead of $25 \mathrm{kA}$ ) if SFCLs are used. The "intangible" value of SFCLs, such as the potential for increased security of supply, increased power quality, and perhaps reduced losses (because of the reduced system impedance due to increased interconnection) is not evaluated. However, an SFCL may itself add electrical losses and operational costs; these have also been ignored.

Many of these simplifications are justified as being relatively small compared to the variability of the viable cost of an SFCL. This can be estimated, although very approximately, from the range of costs of competing solutions for managing fault levels [5], [6]. If SFCLs can be offered at the lower cost levels, their adoption is likely to be high.

\section{Technical issues with fault current limitation}

The protection and control issues described in this section all relate to the inherent operation of an SFCL during a fault, or any system transient that leads to current in excess of the superconductor's critical current value. During a fault, the superconductor in a resistive SFCL will rapidly transit from the superconducting state to a resistive state. However, up to several minutes may be required for recovery to the superconducting state [10]. It is assumed that the SFCL should be removed from service during this period; however the possibility of recovery under load (RUL) is being explored [9]. The potential for SFCLs to interfere with the operation of overcurrent and distance protection schemes has been discussed in [2], [7], [8]; this paper will focus on other issues relevant to utilities.

A case study network has been used to demonstrate the protection issues for a DG connection via an SFCL, as illustrated in Figure 2. It is assumed that the DG would increase the fault level in the local vicinity to a level beyond the rating of existing switchgear, and hence the SFCL is necessary to curb the generator's fault level contribution. It is also assumed that circuit breakers are installed on each feeder, and isolators are located in series with the SFCL. The SFCL may also be installed on the generator side of the connecting transformer.

Note that simple scenarios are considered in this paper and other factors may need to be considered in detail, such as: power quality; undervoltage and underfrequency protection; the type of distributed generation and whether it is centrally despatchable or not; regulatory issues; and the stability of the DG/islanded system (such as lack of voltage control and loss of synchronism) as well as the grid. Other SFCL locations are also likely [2], [10]. In particular, the bus-tie location, as described in [3], is expected to minimise the effects of SFCLs on existing protection systems [2], as well as significantly reducing fault currents.

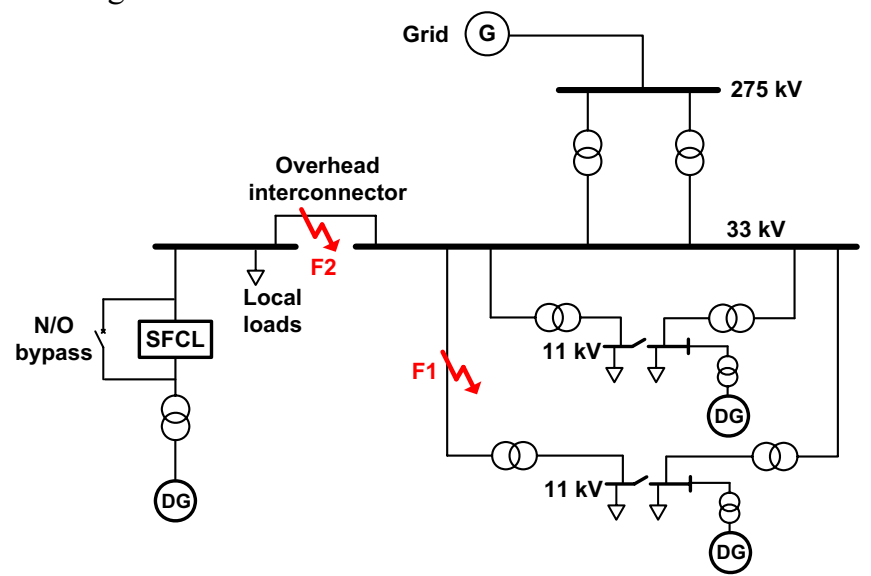

Figure 2: DG connected to the grid via an SFCL

\subsection{SFCL issues for remote faults}

The requirement for DG ride-through during remote faults may be problematic for systems that incorporate SFCLs. First, considering a permanent fault at F1 in Figure 2, which is assumed to be on an underground cable feeder, the DG may be required to ride-through this disturbance while the fault is cleared by the appropriate network protection scheme. However, the SFCL may operate, which (although necessary) consequently requires disconnection of the SFCL (and DG) for recovery. There are several potential solutions to this problem:

- An SFCL that does not require a recovery period could be used, such as a DC-biased pre-saturated iron-core device [10].

- Faster-acting protection schemes could help reduce the energy absorbed by the SFCL and potentially reduce its recovery time. However, circuit breaker operation time (several cycles) relative to SFCL operation time (subcycle) may diminish the net benefit achieved by reducing fault detection and location times.

- The act of removing the faulted feeder from service (e.g., the feeder with fault F1 in Figure 2) may reduce the fault level at the $33 \mathrm{kV}$ busbar, thereby allowing the SFCL to remain out of service while recovering (with the normally-open bypass being used to enable the DG to remain in service). Furthermore, before activating the bypass, network automation could manipulate normallyopen/closed points to reduce the prevailing fault level (possibly at the expense of security of supply and power quality) [6]. This would also allow the SFCL to be removed from service for maintenance. Such a scheme may require relatively low-latency communications between intelligent electronic devices (IEDs) throughout the system.

- As described earlier, SFCLs may be able to recover under load. The option for RUL will help SFCLs to gain favour with utilities [9], but many system-wide effects must be studied, such as the extent and duration of the voltage drop across the SFCL during recovery. 
- Energy storage could potentially be integrated with protection to support loads during the recovery time.

- It may be deemed acceptable to remove the DG (and shed some loads, if required) during SFCL recovery, because such faults are rare and some disturbance should be expected.

Second, many faults on distribution-level overhead lines are transient in nature and hence supply can often successfully be restored by automatic reclosing schemes [1]. Multi-shot reclose schemes may also be used on distribution lines, particularly if there is a high occurrence of semi-permanent faults. The requirement for reclosure capability further complicates the issues described for DG fault ride-through with fault current limitation.

For transient or semi-permanent faults, such as F2 in Figure 2, the SFCL will become resistive and limit the fault current during the protection operating time of the initial trip (see Figure 3). However, the SFCL may not recover to the superconducting state during the dead time, therefore delaying supply restoration unduly. Although increased dead time may increase the chance of a successful reclosure (because the arc has longer to de-ionise, which is increasingly important at higher voltages), it is unlikely that typical dead times (perhaps several seconds at most [1], [4]) will be sufficient to permit SFCL recovery.

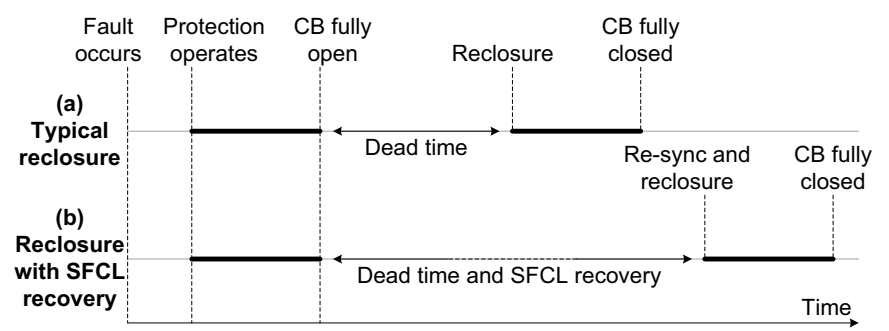

Figure 3: Comparison of simplified reclosure times for a transient fault

Further potential solutions to SFCL issues during transient faults include:

- In some cases the DG must be disconnected during the dead time, regardless of the desirable ride-through or reclosing strategy, to prevent damage due to out-of-sync reclosure [4]. Alternatively, the subsystem could operate islanded: the SFCL's normally-open bypass could be closed to supply the local loads from the DG. This assumes that the DG is necessary to supply the local loads, to prevent load shedding. Islanding should prevent fault level violations, and the island can be reconnected to the grid when the SFCL recovers (by attempting to reclose on the faulted feeder). Clearly many other issues exist with islanding, particularly resynchronisation with the grid.

- An additional SFCL in its superconducting state (or another element in a dual-element unit) could be connected during the dead time. This may significantly increase capital and operational costs, and may still be insufficient to support multi-shot reclosure schemes.

- A resistive or reactive SFCL bypass could also reduce the DG's fault level contribution, but the associated voltage drop may be unsatisfactory; there may also be overheating problems. However, the voltage drop could be compensated with a tap changer transformer managed by a local automation scheme.

\subsection{Protection mal-operation by non-fault transients}

The large currents seen during non-fault transients, such as transformer inrush and motor starts, could cause SFCLs to operate spuriously [11]. Transformer protection uses harmonic restraint to block trips during inrush [1]; this is not relevant for SFCLs. In some circumstances it may be desirable to dampen inrush with an SFCL, but the current should not be sufficient to require recovery to the superconducting state [3], [11].
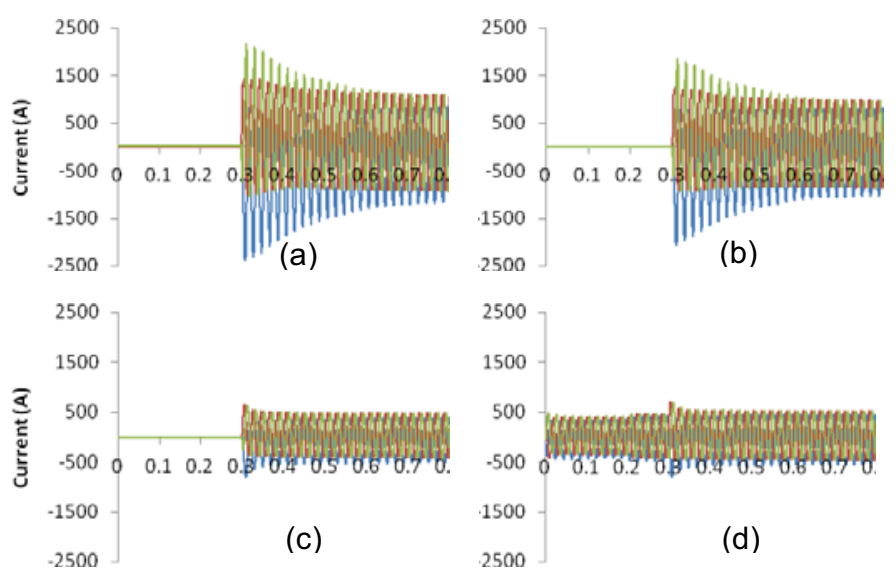

Figure 4: Typical inrush current with DG disconnected (top) and with islanding (bottom)

For a simple radial network such as Figure 2, the effect of transformer inrush was simulated for a "black start" of the network (i.e., reconnection of the grid infeed), with and without DG connected. Figure 4 shows the currents for a black start at 0.3 seconds at (a) a grid infeed transformer (at the $33 \mathrm{kV}$ side), and (b) the $33 \mathrm{kV}$ bus. However, if DG is allowed to continue to supply loads (i.e., islanding is permitted), the corresponding "brown start" currents are shown in (c) and (d). Clearly, the inrush currents are significantly reduced, because the $33 / 11 \mathrm{kV}$ transformers remain energised. Note that a very high DG penetration is assumed, to help model local DG clustering.

Figure 5 shows that transformer inrush and certain faults can produce a similar peak current magnitude and DC offset. Hence, SFCLs have the potential to operate spuriously in response to transformer inrush current, albeit under relatively extreme situations. In this case, an SFCL at the $33 \mathrm{kV}$ bus must be designed with a critical current that avoids operation for such currents (from $11 \mathrm{kV}$ faults), and should only operate for faults at the $33 \mathrm{kV}$ level which can result in peak fault current of approximately $18.2 \mathrm{kA}$, as shown in Figure 6. 


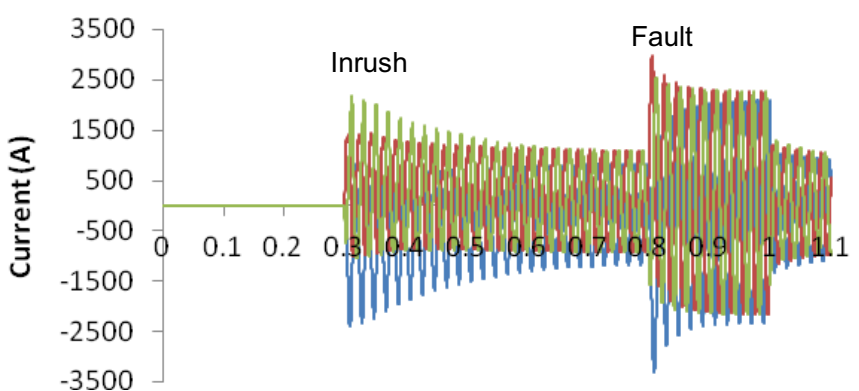

Figure 5: Inrush current at grid infeed compared with a 3phase to earth fault at an $11 \mathrm{kV}$ bus (without DG)

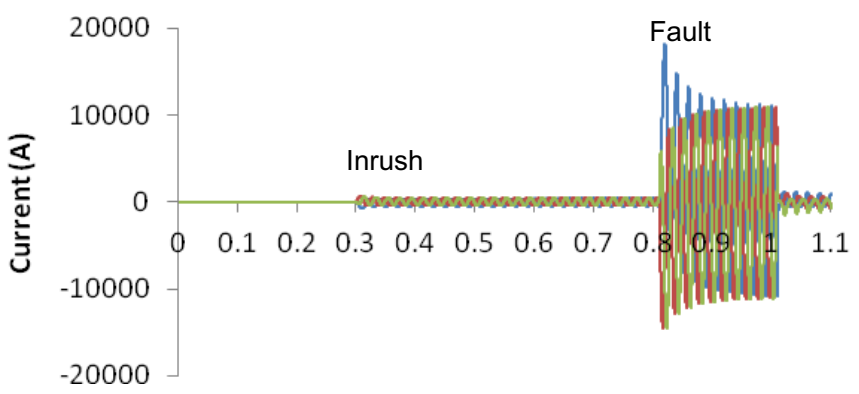

Figure 6: Inrush current at grid infeed compared with a 3phase to earth fault at the $33 \mathrm{kV}$ bus (without DG)

\section{Conclusions}

The statistical analysis presented in this paper illustrates the potential need for fault current limiters in the UK - perhaps several hundred devices - and alludes to a significant worldwide market.

SFCLs can complicate existing protection and control schemes in distribution networks, particularly if the device requires a recovery period. The issues with DG fault ridethrough, auto-reclosure schemes, and transformer inrush are described. Islanding may have a role to play in the practical and economical use of resistive SFCLs. The case study has shown how islanding could help mitigate the recovery time during certain faults, and help mitigate the problem of transformer inrush. Automation schemes could also be used to temporarily manipulate the system topology to reduce the fault level, such that, ideally, all DG remains in service and all loads are supplied while an SFCL recovers. Modelling of typical SFCL operation and recovery time characteristics is needed in future studies to better understand the interaction between SFCLs and protection and control schemes.

\section{Acknowledgements}

This work was carried out within the Rolls-Royce University Technology Centre at the University of Strathclyde. The authors gratefully acknowledge the funding and support offered by Rolls-Royce.

\section{References}

[1] Areva. "Network Protection \& Automation Guide", ISBN: 2951858906, (2005).

[2] S. Blair, N.K. Singh, C. Booth, and G. Burt. "Operational Control and Protection Implications of Fault Current Limitation in Distribution Networks", Proceedings of the 44th International Universities Power Engineering Conference, University of Strathclyde, (2009).

[3] R. Dommerque, et al. "First Commercial Medium Voltage Superconducting Fault-Current Limiters Production, Test and Installation", IEEE/CSC \& ESAS European Superconductivity News Forum (ESNF), (2010).

[4] R. Dugan and T. McDermott. "Distributed generation", IEEE Industry Applications Magazine, vol. 8, pp. 19-25, (2002).

[5] EPRI. "Fault Current Management Guidebook", Technical Update, Document ID: 1012419, (2006).

[6] KEMA. "The contribution to distribution network fault levels from the connection of distributed generation", BERR, Contract number: DG/CG/00027/00/00. URN number: 05/1249, (2005).

[7] J. Langston, M. Steurer, S. Woodruff, T. Baldwin, and J. Tang. "A generic real-time computer Simulation model for Superconducting fault current limiters and its application in system protection studies," IEEE Transactions on Applied Superconductivity, vol. 15, pp. 2090-2093, (2005).

[8] B.W. Lee, J. Sim, K.B. Park, and I.S. Oh. "Practical Application Issues of Superconducting Fault Current Limiters for Electric Power Systems", IEEE Transactions on Applied Superconductivity, vol. 18, pp. 620-623, (2008).

[9] J.H. Llambes, D.W. Hazelton, and C.S. Weber. "Recovery Under Load Performance of 2nd Generation HTS Superconducting Fault Current Limiter for Electric Power Transmission Lines", IEEE Transactions on Applied Superconductivity, vol. 19, pp. 1968-1971, (2009).

[10]M. Noe and M. Steurer. "High-temperature superconductor fault current limiters: concepts, applications, and development status", Superconductor Science and Technology, vol. 20, pp. R15-R29, (2007).

[11]P. Tixador. "High Temperature Superconductivity 2", Springer, ISBN: 3540406396, p. 12, (2004).

[12]UK Statute Law. "Climate change act 2008," UK Government, (2008). 